\title{
Effect of Clinical Experience on Accuracy and Reliability of Radiographic Caries Detection
}

\author{
Efecto de la Experiencia Clínica en la Precisión y Concordancia \\ de Detección de Caries en Radiografías
}

\author{
Juan Estay'; Cristian Bersezio"; Roque Arias'; Eduardo Fernández¹; Osmir Batista Oliveira Junior²; Marcelo \\ Ferrarezi de Andrade $^{2} \&$ Camila Corral Núñez ${ }^{1}$
}

ESTAY, J.; BERSEZIO, C.; ARIAS, A.; FERNANDEZ, E.; OLIVEIRA JUNIOR, O.; FERRAREZI DE ANDRADE, M. \& CORRAL-NUÑEZ, C. Effect of clinical experience on accuracy and reliability of radiographic caries detection. Int. J. Odontostomat., 11(3):347-352, 2017.

\begin{abstract}
The purpose of this study was to investigate the accuracy and interobserver reliability of examiners with different levels of clinical experience, when diagnosing radiographic proximal caries lesions. Bitewing radiographs were selected from a patient attending Operative Dentistry Clinic, Universidad de Chile. Radiographic examination was performed by three different groups: A: third year dentistry students, B: fourth year dentistry students, and C: dentist recently graduated. Thirty-two proximal surfaces were scored as: 0, sound; 1 : enamel caries; and 2: dentinal caries. The data were analysed and accuracy and interexaminer reliability were calculated. Accuracy values for enamel caries were: A (0.54), B (0.55) and C (0.58), and dentinal caries were: A (0.55), B (0.61) and C (0.63). Interexaminer reliability denoted marginal agreement for all groups, $A(0.249)$, B (0.213) and C (0.282) for enamel caries and A (0.058), B (0.102), and C (0.344) for dentinal caries. The results of this study indicate that the accuracy and interexaminer reliability of bitewing radiographic examination were influenced by the clinical experience when detecting radiographic proximal caries, however low values of accuracy and interexaminer reliability were noted, reinforcing the necessity of improving education and training in radiographic caries detection.
\end{abstract}

KEY WORDS: dental caries; bitewing radiography; ROC curve.

\section{INTRODUCTION}

To detect caries lesions as early as possible is one of the main focuses for the current management of caries disease. At early stages, these lesions are non-cavitated, asymptomatic and difficult to detect clinically to the naked eye (Nyvad, 2004). In visualtactile examination, carious lesions are detected by inspection using a probe and a dental mirror. This method is quick, easy and affordable; however, for proximal areas this can be challenging due to may be masked by contact with the adjacent teeth (Haak et al., 2002). In addition, caries lesions can extend into the dentin without causing a visible cavitation (Akpata et al., 1996). Therefore, an accepted method for proximal caries detection involves a combination of visual-tactile examination and radiographic examination, with bitewing radiographs for assessment of proximal lesions (Pitts, 1996; Rindal et al., 2010).
It is of paramount importance that dental students be taught the skills to interpret bitewing radiographs. In addition, it is expected that the interpretation of dental students and dentists with greater clinical experience be as accurate and consistent as possible. However, similar to other diagnoses, the interpretation is subject to error and may lead to over- or under-treatment. Previous studies have reported wide variability of diagnostic accuracy for detection of caries on radiographs, and indicated that education and experience play a role in improving caries detection, however failed to achieve an acceptable range (Diniz et al., 2010; Shams et al., 2016). It is also known that the reliability of interpretation of dental radiographs may be affected by the education, training and experience of the observers, the quality of radiographs, the viewing environment and examiner knowledge of the subject matter (Valachovic et al.,

\footnotetext{
${ }^{1}$ Department of Restorative Dentistry, Faculty of Dentistry, Universidad de Chile, Santiago, Chile.

${ }^{2}$ Department of Restorative Dentistry, School of Dentistry, Universidade Estadual Paulista-UNESP, Araraquara, Brasil.
} 
1986; Rohlin et al., 1991; Stheeman et al., 1995). Therefore, investigate the effect of training and experience is interesting in bitewing radiograph assessment.

To the best of our knowledge, studies on the effects of clinical experience on diagnoses performance for proximal caries detection are scarce. Therefore, the purpose of this study was to investigate the accuracy and inter observer reliability of examiners with different levels of clinical experience. The hypothesis of this study is that the clinical experience of the examiners improves their accuracy and inter examiner reliability in detecting radiographic proximal caries lesions.

\section{MATERIAL AND METHOD}

Test image. Bitewing radiography set of an adult patient (male, 38-year-old) at the Operative Dentistry Clinic, University of Chile, was selected. The patient had a DMFT index corresponding to the average of the Chilean population (DMFT 14) (Urzua et al., 2012), according to a clinical examination conducted by an experienced professor. The bitewing radiographies were taken using a film holder, an x-ray machine (Sirona Heliodent Vario, Sirona Drive Suite 100 Charlotte, NC 28273, USA) at $65 \mathrm{kV}, 7 \mathrm{~mA}$ and exposure time of $0.63 \mathrm{~s}$ for molars and $0.5 \mathrm{~s}$ for premolars.

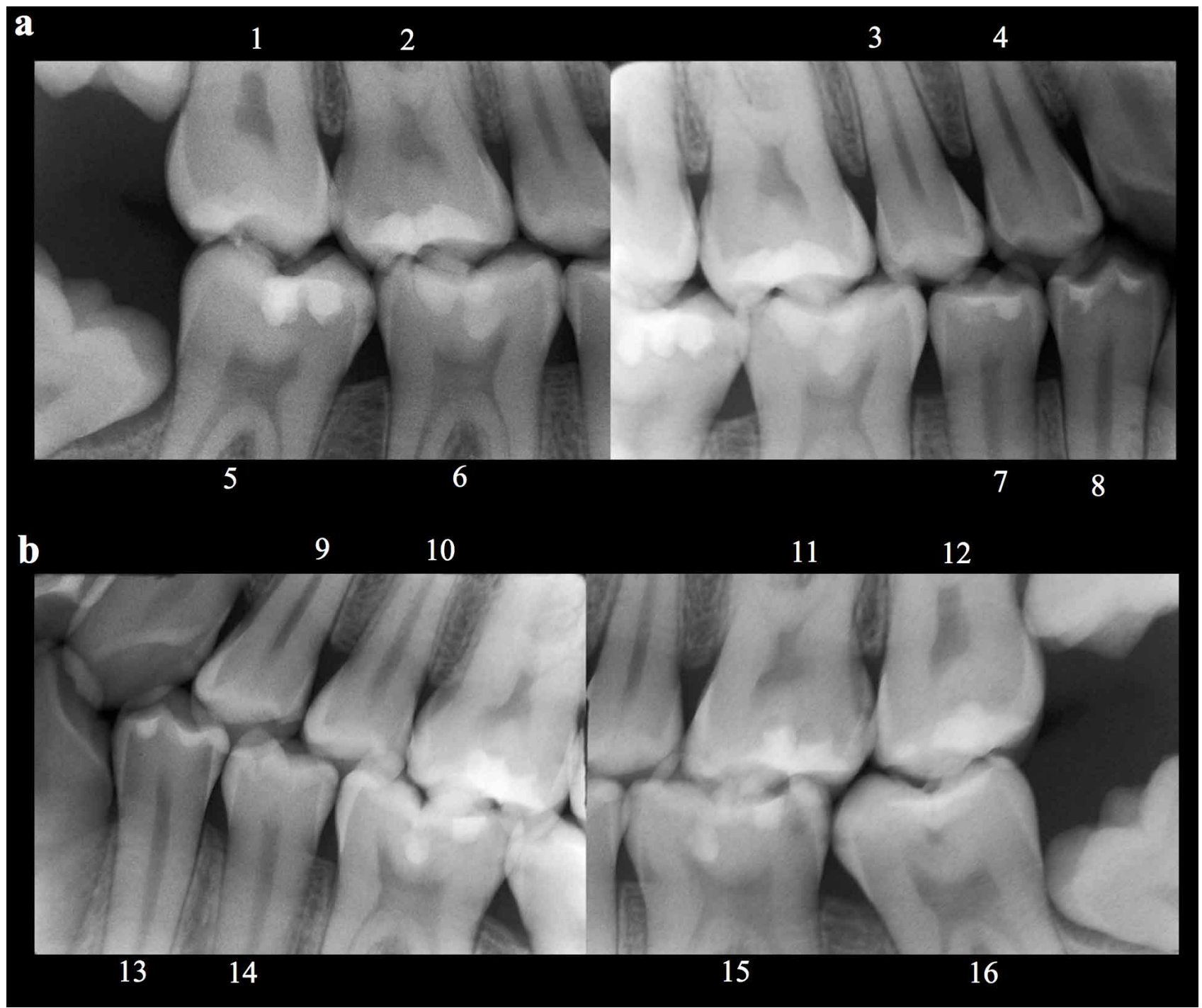

Fig. 1. Bitewing radiograph set selected for evaluation. (a) Right and (b) left premolars and molars, the teeth evaluated are numbered. 
Digital images of the radiography set were obtained scanning the films with Roviscan (Posdion Co., Korea) at $600 \mathrm{dpi} / 14 \mathrm{bits}$. The images are shown in Figure 1. The images were first assessed by a group of four experienced Dental and Maxillofacial Radiology specialists (with 1998 hours of specialist training and at least five years of experience as specialist). The images were displayed without any information such as name, gender, age or clinic history on a Laptop 15.5" 16: 9 (Sony Vaio SVS151A11U) with a resolution of $1920 \times 1080$ pixels (image size $16.27 \times 11.44 \mathrm{~cm}$ ). The laptop was placed on a comfortable desktop in a dark environment. Through consensus, they determined the presence or absence of proximal caries in the premolar and molar proximal surfaces, using the following scale: 0 , sound; 1 : enamel caries; 2 : dentinal caries. Due to the nature of this in vivo study, this assessment was defined as the reference standard (Ferreira et al., 2006).

Experimental Groups. Three different groups of examiners assessed the bitewing radiographs, arranged as follow:

Group A. Third-year dental students $(n=60)$, without clinical experience.

Group B. Fourth-year dental students $(n=60)$, with 884 $\mathrm{h}$ of clinical experience.

Group C. Dentists (general practitioners) recently graduated $(n=60)$, with at least $2250 \mathrm{~h}$ of clinical experience.

The examiners did not receive an additional training or calibration in interpretation of bitewing radiographs. Each examiner performed radiographic examination after instructed through oral orientation to consider proximal surfaces of premolars and molars, excepting third molars (32 proximal surfaces), and classify into 0 : sound; 1 : proximal radiolucency in enamel (enamel caries) and 2: proximal radiolucency in dentine (dentinal caries). To facilitate the radiographic examination and avoid errors outside the examination type, each tooth was numbered, and there was no time limit. First, images of the right region (molars and premolars) and then the left region were shown (Fig. 1 ). The images were displayed following the same protocol used with the group of radiology specialists.
Data analysis. Using the consensus of the four Dental and Maxillofacial Radiology specialists as a reference standard, the receiver operating characteristic (ROC) curve was calculated for each observer, in which the area under the curve was interpreted as accuracy. The Shapiro-Wilk test was used to assess the distribution of the sample and pairwise comparison of ROC curves was performed at enamel and dentin thresholds, by Mann-Whitney test using IBM SPSS Statistics v.21.0 (SPSS Inc. ChicagoIL-USA).

The inter observer reliability was calculated using the Fleiss' Kappa value for each experimental group. Kappa values above 0.75 denoted excellent agreement, while values between 0.40 and 0.75 indicated good agreement, and less than 0.40 denote marginal agreement (Fleiss, 1981).

\section{RESULTS}

In this study, from the 32 proximal surfaces analysed, the consensus of the radiologist specialists revealed that nine $(28.1 \%)$ were caries free, 19 (59.3 $\%$ ) had caries lesions restricted to enamel, and 4 (12.5 $\%$ ) had dentinal caries lesions. Thus, a total of 23 $(71.8 \%)$ surfaces were considered to be positive for caries lesions.

The demographic characteristics of the examiners groups are shown in Table I. The accuracy values, according to the type of caries lesions for all groups are summarized in Table II. The best value of accuracy was presented by the group of dentists $(0.58$ and 0.63 for enamel and dentinal caries respectively).

Inter examiner reliability shown as Fleiss's kappa values are presented in Table III. For enamel caries lesions, groups $\mathrm{A}$ and $\mathrm{C}$ presented the highest kappa, statistically significant higher than group B. However, for dentinal caries lesions group $C$ presented the highest kappa, followed by group B and A. Overall, for the three groups, the inter examiner reliability denoted marginal agreement $(<0.40)$.

Table I. Descriptive characteristics of examiners groups.

\begin{tabular}{lccccc}
\hline Examiners & \multicolumn{2}{c}{$\mathrm{n}(\%)$} & \multicolumn{2}{c}{ Age (years) } \\
\cline { 2 - 5 } groups & male & female & total & male & female \\
\cline { 2 - 6 } A & $28(46.6 \%)$ & $32(53.3 \%)$ & 60 & 21.2 & 20.9 \\
B & $31(51.6 \%)$ & $29(48.3 \%)$ & 60 & 22.4 & 21.8 \\
C & $27(45 \%)$ & $33(55 \%)$ & 60 & 24.5 & 24.2 \\
\hline
\end{tabular}


Table II Average accuracy of radiographic examination for caries detection of the different examiners groups.

\begin{tabular}{ccc}
\hline Examiners groups & \multicolumn{2}{c}{ Accuracy } \\
& Enamel & Dentin \\
\hline A & $0,54(0,067)^{\mathrm{a}}$ & $0,55(0,08)^{\mathrm{a}}$ \\
$\mathrm{B}$ & $0,55(0,075)^{\mathrm{ad}}$ & $0,61(0,11)^{\mathrm{D}}$ \\
C & $0,58(0,08)^{\mathrm{b}}$ & $0,63(0,14)^{\mathrm{b}}$ \\
\hline
\end{tabular}

Within columns, different letters indicate values with statistically significant difference $(p<0.05)$.

Table III. Fleiss' Kappa values for interexaminer reliability of the different groups.

\begin{tabular}{ccccccc}
\hline Examiners groups & \multicolumn{2}{c}{ Reliability } & \multicolumn{2}{c}{ Dentin } & SE \\
& Kappa & Enamel & SE & Kappa & Cl & SE \\
A & $0.249^{\mathrm{a}}$ & $0.227-0.272$ & 0.012 & $0.058^{\mathrm{a}}$ & $0.037-0.076$ & 0.012 \\
B & $0.213^{\mathrm{b}}$ & $0.196-0.230$ & 0.009 & $0.102^{\mathrm{b}}$ & $0.086-0.119$ & 0.008 \\
C & $0.282^{\mathrm{a}}$ & $0.248-0.316$ & 0.017 & $0.344^{\mathrm{c}}$ & $0.310-0.377$ & 0.017 \\
\hline
\end{tabular}

Within columns, different letters indicate values with statistically significant difference $(p<0.05)$.

\section{DISCUSSION}

There are few studies concerning the process of learning and developing diagnostic skills in radiographic interpretation (Wrbas et al., 2000; Mileman et al., 2004; Shams et al.). In this study, we aimed to evaluate the differences presented between dental students and graduated dentist with greater clinical experience, when detecting proximal caries lesions in bitewing radiographs. The results obtained showed better accuracy in graduated dentists, however, both professionals and dental student showed poor agreement in their radiographic diagnoses.

The third-year dental students included in this study have received theoretical knowledge through a one-year Dental Radiology course. In contrast, fourthyear dental students have an additional 884 hours of clinical practice and recently graduated dentists have completed a total of at least 2250 clinical hours. Therefore, the presented results seem to indicate that clinical experience plays a significant role in improving accuracy when diagnosing proximal caries lesions. These results, similarly to findings of Hellén-Halme and Petersson (Hellen-Halme \& Petersson, 2010) indicate that theoretical knowledge is not in itself enough, and practice and experience are essential for detecting the presence of a carious lesion. The daily practice of removing caries lesions, while correlating it to their radiographic image, probably allows a better understanding of caries radiographic progression (Hellen-Halme \& Petersson). In addition, it is suggested that dental students might have a greater tendency for false positives, since they have recently learned that every disease must be detected and properly treated, and for them not detecting a caries lesion could be considered a big error (Diniz et al.).

Other studies have evaluated whether education level and experience can affect diagnostic accuracy of caries lesions in radiographs (Lazarchik et al., 1995; Mileman \& van den Hout, 2002; Hellen-Halme \& Petersson). Hellen-Halme \& Petersson reported that experienced dentists diagnosed radiographic proximal caries more accurately than dental hygiene students and dentistry students. Likewise, Mileman \& van den Hout found better specificity in dentists than in dentistry students. However, they also showed worse sensitivity. The better sensitivity of the students in that work was explained as a consequence of a more liberal cut-off point in the student group (Mileman \& van den Hout). Diniz et al. reported similar values of accuracy for dental practitioners and students for recognizing dentine caries from bitewing radiographs.

In the present study accuracy and interexaminer reliability were considered low, denoting marginal agreement (Fleiss). Similar results have been reported by Diniz et al. even with dentists with 5-7 years of experience. Comparable to this study, in the above mentioned study the majority of lesions were restricted to the enamel tissue, and this fact was stated to 
ESTAY, J.; BERSEZIO, C.; ARIAS, A.; FERNANDEZ, E.; OLIVEIRA JUNIOR, O.; FERRAREZI DE ANDRADE, M.; CORRAL-NUÑEZ, C. Effect of clinical experience on accuracy and reliability of radiographic caries detection. Int. J. Odontostomat., 11(3):347-352, 2017.

explained the low agreement values obtained (Diniz et al.). In contrast, in the studies of Lussi et al. (1995) and Ricketts et al. (1994), higher proportion of surfaces had deep dentinal caries and high sensitivity values were obtained. Therefore, a better performance could be expected if deeper caries lesions were included.

To accomplish an effective training in radiography interpretation, there should be numerous opportunities of corrective feedback (Wrbas et al.). During the education process of dental students, possibilities to compare clinical and radiographic image of caries lesions could be offered by the aid of computer-aided learning (Mileman et al., 2003, 2004; Wenzel, 1995). Unfortunately, other alternatives to improve skills of additional didactic instruction, based on lectures and discussion of case reports has not proven to be very effective (Wrbas et al.). Therefore, in order to raise the educational level in dental radiographic diagnosis, activities that aim to replicate the learning achieved by clinical experience, comparing clinical and radiographic outlining of lesions, could be suggested (Wrbas et al.).

The set of bitewing radiography chosen was not selected from a radiography bank, but from a real patient, taken under normal conditions. Other published studies assessing this issue have preferred the use of simulated bitewing radiographs taken from extracted teeth (Mileman \& van den Hout; Hellen-Halme \& Petersson). This has the potential benefit that later, the extracted teeth can be assessed with histological methods and these results used as a reference standard. The condition of not using bitewing radiographs from a bank can also be acknowledged as a positive innovation of this study. In their daily practice, clinicians are confronted with radiographs taken from real-life patients, which present differences in alignment of the teeth, bone structure, that are difficult to mimic with extracted teeth mounted on a cast.

Some possible limitation of the present study is the use of digitized radiographs. These images could add difficulties to the detection of lesions, due to reported increased physical noise of the radiographic image. (Wenzel et al., 1993; Møystad et al., 1996; Hintze et al., 2002) However, Prapayasatok et al. (2006) and Kimmes et al. (2006) did not report differences between digitized and conventional radiographs for caries detection, and it was stated that these images could be used for diagnosis.

In conclusion, based on the methodology used in this study, the accuracy and interexaminer reliability of bitewing radiographic examination were influenced by the clinical experience when detecting proximal caries. Low values of accuracy and interexaminer reliability were noted, reinforcing the necessity of improving education and training in radiographic caries detection. This study demonstrates the need for training and continuous learning for undergraduate students and dentists in order to improve performance in detecting radiographic caries lesions.

ESTAY, J.; BERSEZIO, C.; ARIAS, A.; FERNANDEZ, E.; OLIVEIRA JUNIOR, O.; FERRAREZI DE ANDRADE, M.; CORRAL-NUÑEZ, C. Efecto de la experiencia clínica en la precisión y concordancia de detección de caries en radiografías. Int. J. Odontostomat., 11(3):347-352, 2017.

RESUMEN: El objetivo de este trabajo fue evaluar la precisión y concordancia entre examinadores con distinto nivel de experiencia clínica, al diagnosticar lesiones de caries proximales en radiografías. Un set de radiografías bitewing fue seleccionado de un paciente que acudió a la Clínica de Operatoria de la Facultad de Odontología, Universidad de Chile. El examen radiográfico fue realizado por tres grupos distintos: A: estudiantes de Odontología de tercer año, B: estudiantes de Odontología de cuarto año, y C: dentistas recientemente graduados. Treinta y dos superficies proximales fueron analizadas y evaluadas como: 0 , sana; 1: lesión de caries de esmalte, 2: lesión de caries dentinaria. Los datos obtenidos fueron analizados y la precisión y concordancia entre examinadores fueron calculadas. Los valores de precisión en lesiones de esmalte fueron: $A(0,54), B(0,55)$ y $C$ $(0,58)$, y para lesiones dentinarias fueron: $A(0,55), B(0,61)$ y C $(0,63)$. La concordancia entre examinadores denotó ser marginal para todos los grupos, $A(0,249), B(0,213)$ y $C(0,282)$ en lesiones de esmalte y $A(0,058), B(0,102)$, y $C(0,344)$ en lesiones dentinarias. Los resultados de este estudio indican que la precisión y la concordancia entre examinadores está influenciada por la experiencia clínica, sin embargo los valores encontrados fueron bajos, lo que refuerza la necesidad de mejorar la educación y entrenamiento en detección de lesiones de caries en radiografías.

PALABRAS CLAVE: caries dental, radiografía bitewing, curva ROC.

\section{REFERENCES}

Akpata, E. S.; Farid, M. R.; al-Saif, K. \& Roberts, E. A. Cavitation at radiolucent areas on proximal surfaces of posterior teeth. Caries Res., 30(5):313-6, 1996.

Diniz, M. B.; Rodrigues, J. A.; Neuhaus, K. W.; Cordeiro, R. C. \& Lussi, A. Influence of examiner's clinical experience on the reproducibility and accuracy of radiographic examination in 
detecting occlusal caries. Clin. Oral. Investig. 14(5):515-23, 2010.

Ferreira, R. I.; Haiter-Neto, F.; Tabchoury, C. P. M.; de Paiva, G. A. N. \& Boscolo, F. N. Assessment of enamel demineralization using conventional, digital, and digitized radiography. Braz. Oral Res., 20(2):114-9, 2006.

Fleiss, I. L. Statistical Methods for Rates and Proportions. $2^{\text {nd }}$ ed. New York, Wiley, 1981

Haak, R.; Wicht, M. J.; Hellmich, M.; Gossmann, A. \& Noack, M. J. The validity of proximal caries detection using magnifying visual aids. Caries Res., 36(4):249-55, 2002.

Hellen-Halme, K. \& Petersson, G. H. Influence of education level and experience on detection of approximal caries in digital dental radiographs. An in vitro study. Swed. Dent. J., 34(2):63-9, 2010.

Hintze, H.; Wenzel, A. \& Frydenberg, M. Accuracy of caries detection with four storage phosphor systems and E-speed radiographs. Dentomaxillofac. Radiol., 31(3):170-5, 2002.

Kimmes, N. S.; Saini, T. S. \& Carroll, L. R. Comparison of clinician agreement during visualization of conventional and digitized bitewing radiographs. Gen. Dent., 54(3):182-5, 2006.

Lazarchik, D. A.; Firestone, A. R.; Heaven, T. J.; Filler, S. J. \& Lussi, A. Radiographic evaluation of occlusal caries: effect of training and experience. Caries Res., 29(5):355-8, 1995.

Lussi, A.; Firestone, A.; Schoenberg, V.; Hotz, P. \& Stich, H. In vivo diagnosis of fissure caries using a new electrical resistance monitor. Caries Res., 29(2):81-7, 1995.

Mileman, P. A. \& van den Hout, W. B. Comparing the accuracy of Dutch dentists and dental students in the radiographic diagnosis of dentinal caries. Dentomaxillofac. Radiol., 31(1):7-14, 2002.

Mileman, P. A.; van den Hout, W. B. \& Sanderink, G. C. Looking for caries...? Teachers evaluate a program to improve caries diagnosis from radiographs. Eur. J. Dent. Educ., 8(1):35-42, 2004.

Mileman, P. A.; van den Hout, W. B. \& Sanderink, G. C. Randomized controlled trial of a computer-assisted learning program to improve caries detection from bitewing radiographs. Dentomaxillofac. Radiol., 32(2):116-23, 2003.

Møystad, A.; Svanaes, D. B.; Risnes, S.; Larheim, T. A. \& Gröndahl, H. G. Detection of approximal caries with a storage phosphor system. A comparison of enhanced digital images with dental Xray film. Dentomaxillofac. Radiol., 25(4):202-6, 1996.

Nyvad, B. Diagnosis versus detection of caries. Caries Res, 38(3):192-8, 2004.

Pitts, N. B. The use of bitewing radiographs in the management of dental caries: scientific and practical considerations. Dentomaxillofac. Radiol., 25(1):5-16, 1996.

Prapayasatok, S.; Janhom, A.; Verochana, K. \& Pramojanee, S. Digital camera resolution and proximal caries detection. Dentomaxillofac. Radiol., 35(4):253-7, 2006.

Ricketts, D.; Kidd, E.; Smith, B. \& Wilson, R. Radiographic detection of occlusal caries: effect of X-ray beam factors on diagnosis. Eur. J. Prosthodont. Restor. Dent., 2(4):149-54, 1994.

Rindal, D. B.; Gordan, V. V.; Litaker, M. S.; Bader, J. D.; Fellows, J. L.; Qvist, V.; Wallace-Dawson, M. C.; Anderson, M. L.; Gilbert, G. H. \& DPBRN Collaborative Group. Methods dentists use to diagnose primary caries lesions prior to restorative treatment: findings from The Dental PBRN. J. Dent., 38(12):1027-32, 2010.

Rohlin, M.; Kullendorff, B.; Ahlqwist, M. \& Stenström, B. Observer performance in the assessment of periapical pathology: a comparison of panoramic with periapical radiography. Dentomaxillofac. Radiol., 20(3):127-31, 1991.

Shams, N.; Panahandeh, N.; Aghababa, H.; Shams, B. \& Hemati, E. Effects of education and experience on detection of proximal caries on digital radiographs. Oral Radiol., 32(3):154-9, 2016.

Stheeman, S. E.; Mileman, P. A.; van 't Hof, M. A. \& van der Stelt, P. F. Diagnostic confidence and the accuracy of treatment decisions for radiopaque periapical lesions. Int. Endod. J., 28(3):121-8, 1995.
Urzua, I.; Mendoza, C.; Arteaga, O.; Rodriguez, G.; Cabello, R.; Faleiros, S.; Carvajal, P.; Muñoz, A.; Espinoza, I.; Aranda, W. \& Gamonal, J. Dental caries prevalence and tooth loss in chilean adult population: first national dental examination survey. Int. J. Dent., 2012:810170, 2012.

Valachovic, R. W.; Douglass, C. W.; Berkey, C. S.; McNeil, B. J. \& Chauncey, H. H. Examiner reliability in dental radiography. J. Dent. Res., 65(3):432-6, 1986.

Wenzel, A. Current trends in radiographic caries imaging. Oral Surg. Oral Med. Oral Pathol. Oral Radiol. Endod., 80(5):527-39, 1995.

Wenzel, A.; Pitts, N.; Verdonschot, E. H. \& Kalsbeek, H. Developments in radiographic caries diagnosis. J. Dent., 21(3):131-40, 1993.

Wrbas, K. T.; Kielbassa, A. M.; Schulte-Mönting, J. \& Hellwig, E. Effects of additional teaching of final-year dental students on their radiographic diagnosis of caries. Eur. J. Dent. Educ., 4(3):13842, 2000

Corresponding author:

Camila Corral

Department of Restorative Dentistry

Faculty of Dentistry

Universidad de Chile/

PhD Program UNESP Araraquara Brasil

Sergio Livingstone Pohlhammer 943

Independencia

Santiago

CHILE

E-mail: camila.corral@u.uchile.cl

Received: 31-05-2017

Accepted: 19-06-2017 